\title{
THE RESPONSE TO THE ADMINISTRATION OF AN ISOTONIC SODIUM CHLORIDE-LACTATE SOLUTION IN PATIENTS WITH ESSENTIAL HYPERTENSION
}

\author{
By SOLOMON PAPPER,* JOSEPH L. BELSKY AND KENNETH H. BLEIFER $\dagger$ \\ (From the Medical Service and the Research Laboratory, Veterans Administration Hospital, \\ and the Departments of Medicine, Boston University School of Medicine and \\ Tufts University School of Medicine, Boston, Mass.)
}

(Submitted for publication December 21, 1959; accepted January 8, 1960)

Many studies indicate that patients with essential hypertension have a greater natriuretic response to rapidly administered sodium chloride solutions than have normotensive individuals (1-7). However, in most instances other factors known to influence the rate of sodium excretion in the normal subject such as diet, posture, and time of day have not been rigidly controlled $(8,9)$. Dietary control is of particular importance in view of observations suggesting that patients with hypertension may habitually ingest more salt than do normotensive individuals (1011). If this is indeed the case it might well be responsible for the enhanced response of the hypertensive patient to administered salt.

The present report is concerned with a comparison of the response of hypertensive and normotensive individuals to the intravenous administration of an "isotonic-balanced" salt solution under rigidly controlled conditions and at three different levels of dietary salt ingestion. The results indicate that patients with essential hypertension excrete the infused sodium load more rapidly than do normotensive individuals at each level of salt consumption.

\section{METHODS}

Four normal Caucasian males aged 29 to 36 and 6 Caucasian patients aged 24 to 63 with essential hypertension were studied. The patients were selected on the basis of their maintaining a resting diastolic blood pressure of at least $100 \mathrm{~mm} \mathrm{Hg}$ while hospitalized and consuming a diet containing approximately $10 \mathrm{mEq}$ of sodium daily. Five of the 6 subjects were observed in this manner for 13 to 47 days prior to study, while Patient 8 received the low salt diet for 8 days prior to study. No patient had congestive heart failure, although no. 5 had

\footnotetext{
* Present address: Medical College of Virginia, Richmond, Va.

$\dagger$ USAF (MC).
}

had a myocardial infarct 6 years earlier. All 6 had electrocardiographic evidence of left ventricular strain, but were free of gross cardiomegaly on radiographic examination. Three patients had a history of mild hemiparesis 3 months to 10 years before study; Patients 5 and 8 made complete recovery while Patient 9 had mild neurological residua. Ocular fundi varied from normal to Grade $2^{1}$ arteriolar narrowing without hemorrhage, exudate or papilledema. Renal function (including endogenous creatinine clearance, phenolsulfonephthalein (PSP) excretion, intravenous pyelogram and concentration test) was normal except in Patients 9 and 10 who had modest reduction in creatinine clearance.

Three of the 4 normal subjects and 5 hypertensive patients were provided a diet containing 10 to $15 \mathrm{mEq}$ of sodium daily (low salt diet). After equilibrium was established (i.e., a minimum of 4 days of dieting and 2 consecutive days during which time the 24 hour urinary sodium excretion did not exceed $15 \mathrm{mEq}$ ) the following two studies were done within a period of 3 days.

1. "Blank Day." The subject had his usual breakfast including $500 \mathrm{ml}$ of water. At 8 a.m. he assumed the recumbent position and remained so until 3 p.m. except to void. From 10 a.m. to 2 p.m. each subject drank 100 $\mathrm{ml}$ of water hourly and ingested $5 \mathrm{~g}$ of carbohydrate each half hour. Spontaneously voided urine was collected at one-half hour intervals. Venous blood was collected at least twice (10 a.m. and 2 p.m.).

2. "Infusion Day." The protocol was essentially the same as on Blank Day except that $2,000 \mathrm{ml}$ of a solution containing $130 \mathrm{mEq}$ per $\mathrm{L}$ of sodium, $105 \mathrm{mEq}$ per $\mathrm{L}$ of chloride and $25 \mathrm{mEq}$ per $\mathrm{L}$ of lactate was administered intravenously from 10 to $11: 30$ a.m., and hourly drinking commenced at 12 noon. Venous blood samples were collected immediately prior to and at the end of the infusion period and again at 2 p.m. An additional normal subject (no. 4) and one hypertensive patient (no. 10) were studied as described for Infusion Day without a prior Blank Day.

1 The grading system employed is that recommended to the American Ophthalmological Society by the committee on Classification of Hypertensive Disease of the Retina: Wagener, H. P., Clay, G. E., and Gipner, J. F. Classification of retinal lesions in the presence of vascular hypertension. Trans. Amer. Ophthal. Soc. 1947, 45, 57. 


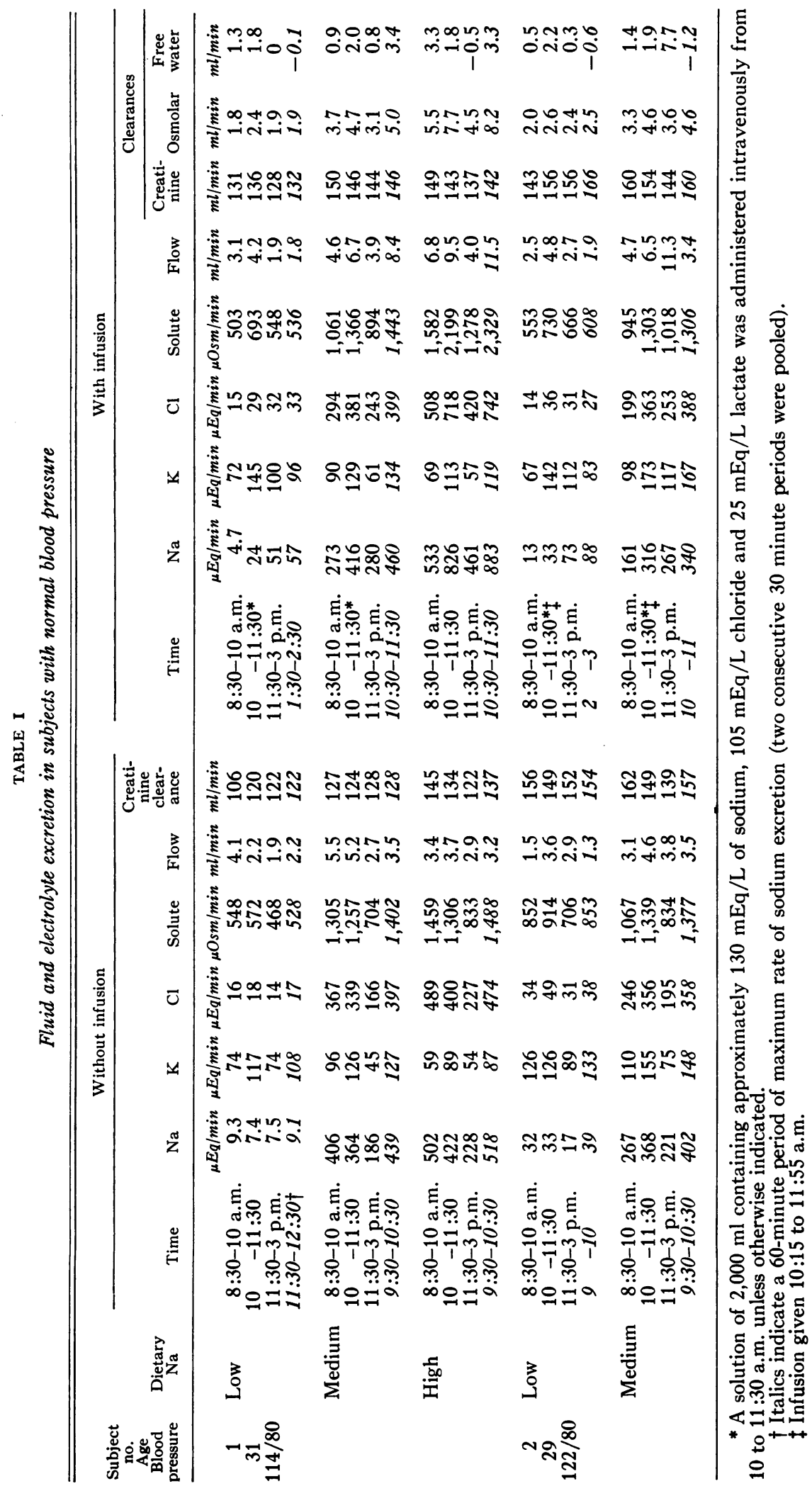




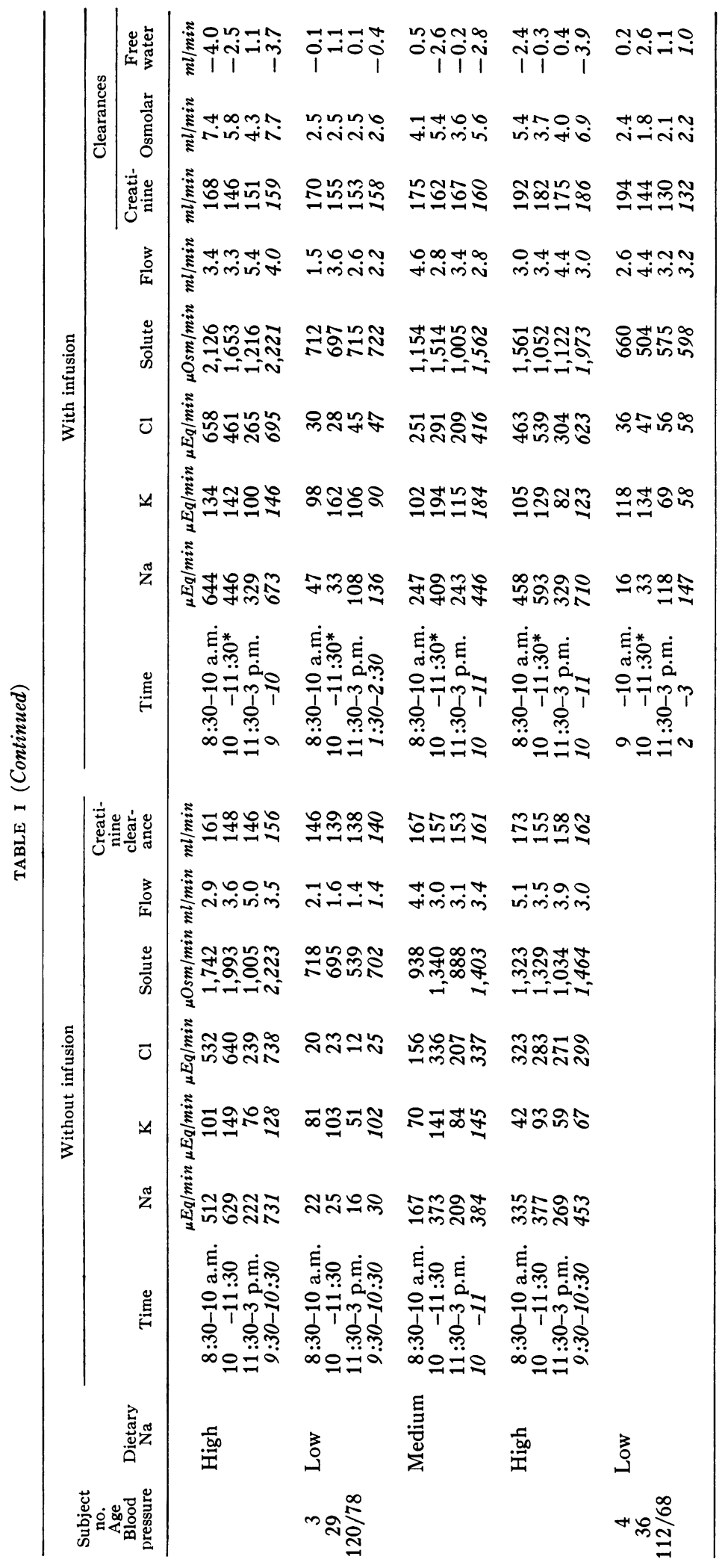


Three normal subjects and three hypertensive patients were similarly studied after equilibrium was established while taking the same $10 \mathrm{mEq}$ sodium diet with approximately $35 \mathrm{mEq}$ of sodium chloride (non-enteric coated tablets) added to each meal and again at bedtime for a total of $150 \mathrm{mEq}$ sodium intake daily (medium salt diet). On both Blank Day and Infusion Day each subject ate his usual breakfast and $35 \mathrm{mEq}$ of additional salt in tablet form. At the end of the Blank Day experimental period, the subjects were given sufficient food and sodium to maintain caloric intake and the $150 \mathrm{mEq}$ daily quantity of sodium.

Three normal subjects and three hypertensive patients were similarly studied while they were taking approximately $300 \mathrm{mEq}$ of sodium daily (high salt diet).

Blood pressure was determined at one-half hour intervals in the hypertensive patients during both experimental days at each dietary level, and less often in the normal subjects.

Serum and urine were analyzed for sodium, potassium, chloride, creatinine and total solute content by methods employed in this laboratory and previously described (12). Serum protein, blood hemoglobin concentration and hematocrit were also determined.

\section{RESULTS}

1. On Blank Day there was no significant difference between the normotensive and hypertensive subjects, taking the low sodium diet, in the quantities of sodium and chloride excreted from 10 a.m. to 3 p.m. In five of six instances, while provided with medium and high salt intakes, the hypertensive patients excreted more sodium and chloride than did the normal individuals from 10 a.m. to 3 p.m. (Tables I and II, Figure 1).

2. On Infusion Day the preinfusion rates of sodium excretion were no higher in the hypertensive than in the normal group at each dietary level of sodium ingestion. In fact, the hypertensive patients had slightly lower rates of sodium excretion prior to infusion while taking the medium salt diet (Tables I and II, Figure 1).

3. In each instance at all levels of salt intake, the hypertensive patient had a far greater natriuresis after intravenous salt loading than had the normal. The maximal rates of sodium excretion after salt loading occurred more promptly in the hypertensive patient at the low level of salt intake (Tables I and II, Figures 1 and 2).

4. By the morning after salt loading the hypertensive patients had excreted more sodium than had the normal subjects at each dietary level. This difference is attributed to the prompt re-

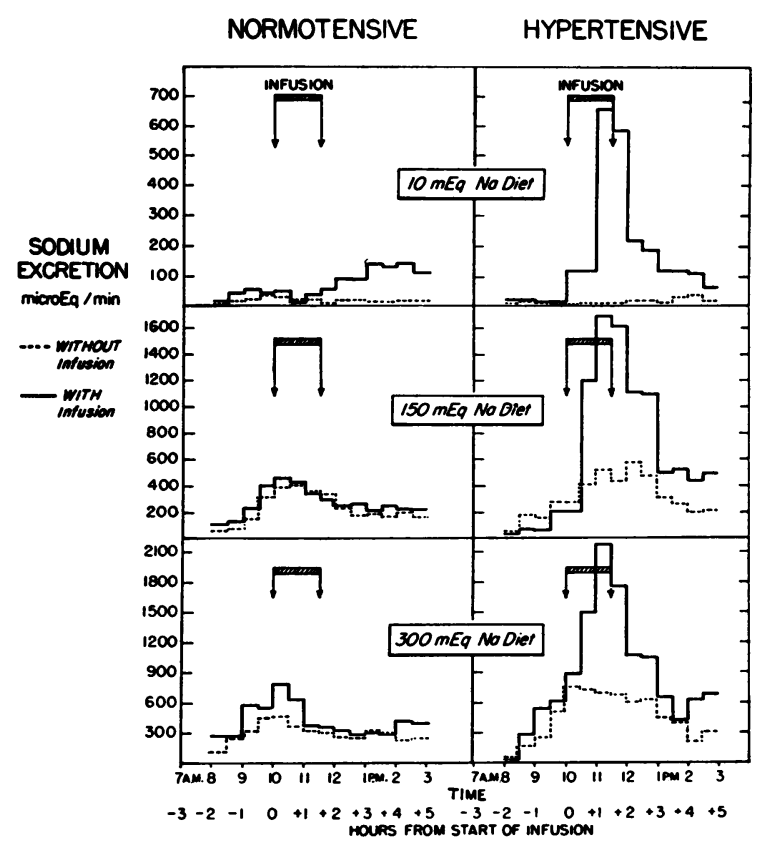

Fig. 1. Sodium EXCRetion With AND Without INFUSION IN ONE NORMOTENSIVE (SUBJECT 3) AND ONE HYPERTENSIVE (SUbject 6) While PROVIDEd With LOW, MEDIUM AND HIGH SALT DIETS. The ordinate scale for the $150 \mathrm{mEq}$ and $300 \mathrm{mEq}$ sodium diets is double and triple, respectively, the scale for the $10 \mathrm{mEq}$ sodium diet.

sponse (10 a.m. to 3 p.m.) rather than to any continued difference in sodium excretion throughout the remainder of the day (Table III).

5. Endogenous creatinine clearance generally increased in both normal and hypertensive subjects when dietary salt was increased from low to medium salt intake levels. The change in clearance was less conspicuous between the medium and high salt intakes. It is also apparent that the $8: 30$ to 10 a.m. endogenous creatinine clearance often varied significantly in the two studies carried out in a single individual on different days. The differences in natriuretic response observed were not consistently or uniformly correlated with preinfusion differences in endogenous creatinine clearance or with change in clearance following infusion (Tables I and II).

6. In nine experiments in patients with hypertension, the infusion of sodium chloride-lactate solution was not associated with a rise in blood pressure. In the remaining two experiments a rise in diastolic blood pressure of 10 to $12 \mathrm{~mm} \mathrm{Hg}$ was observed following infusion. 


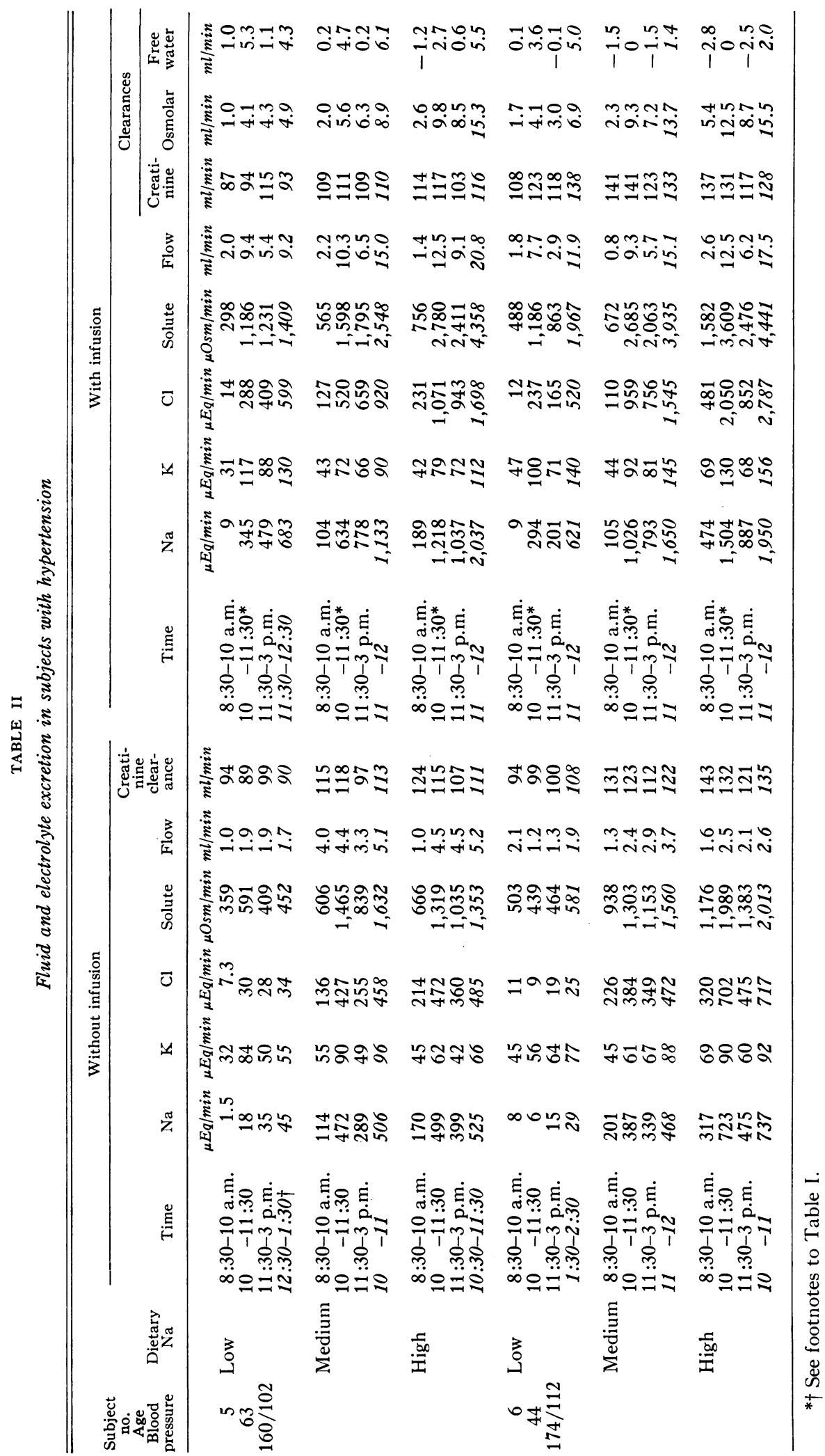




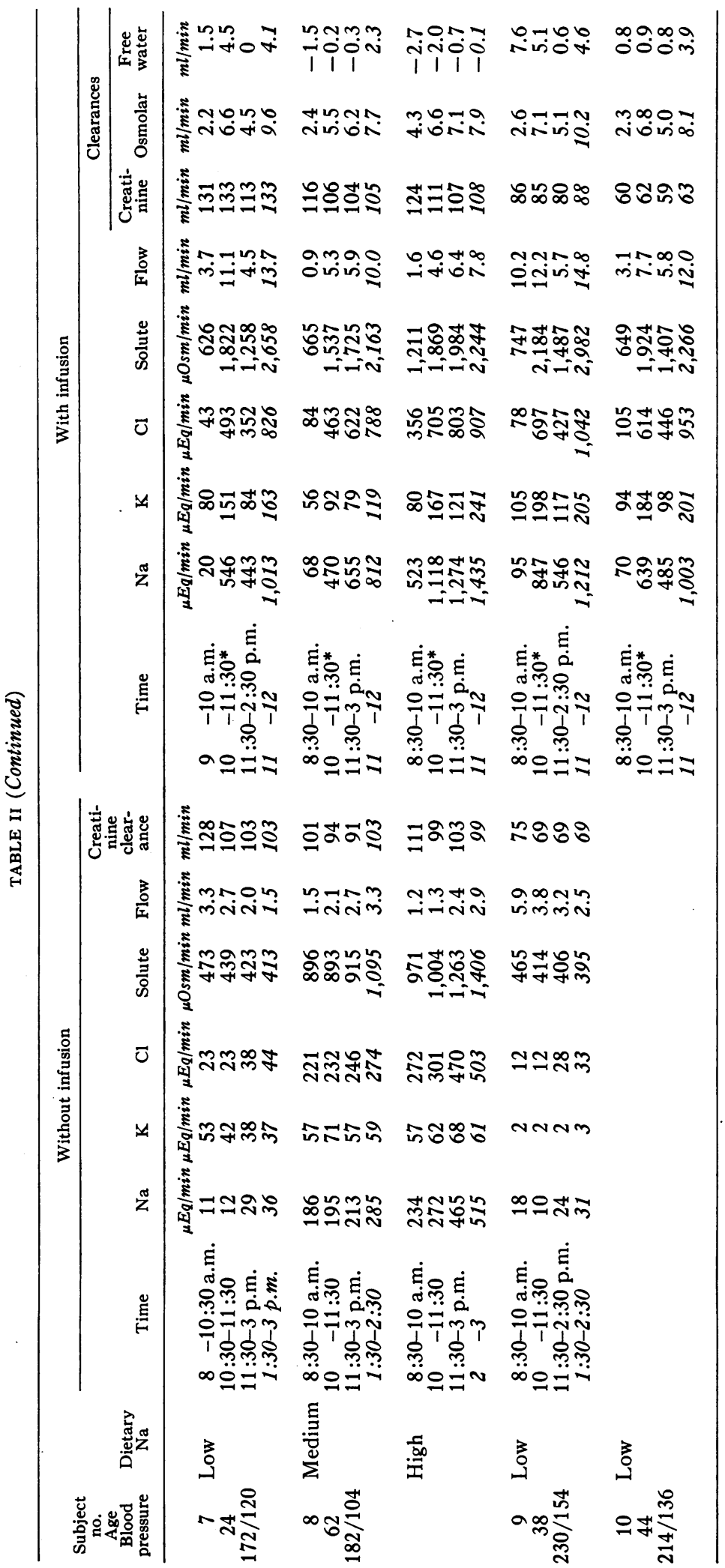




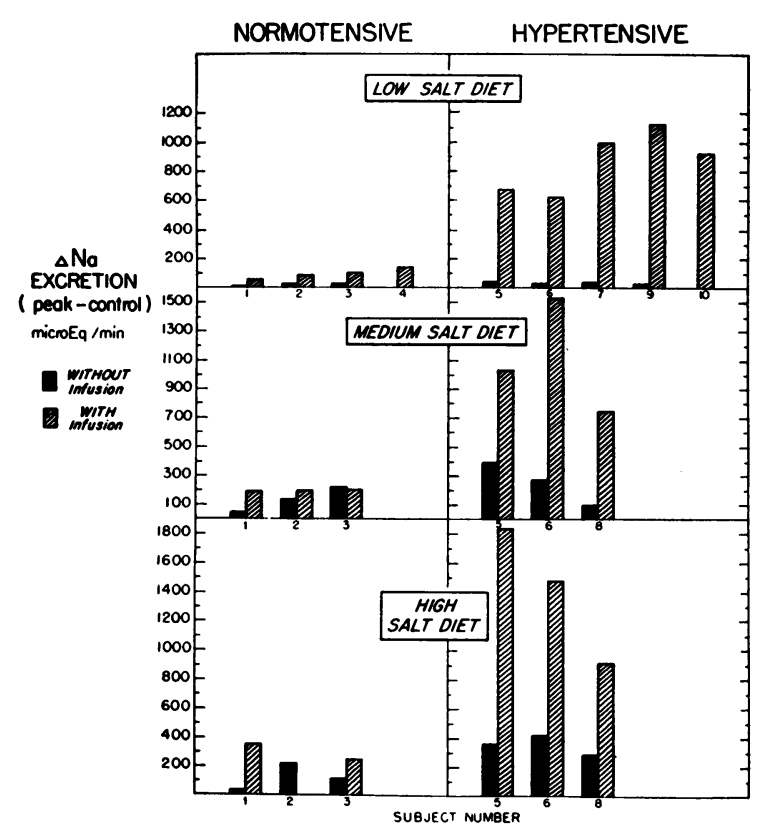

Fig. 2. The Difference IN THE RATE OF SODIUM EXCRETION BETWEEN THE 60 MINUTE PERIOD OF MAXIMUM NATRIURESIS AFTER 10 A.M. AND THE MEAN SODIUM EXCRETION BETWEeN 8:30 AND 10 A.M. (While on a high salt diet, Subject 2 had a maximal natriuresis prior to the infusion period.)

7. Potassium excretion varied considerably but there was no consistent difference between the hypertensive and normotensive subjects (Tables I and II).

8. On Infusion Days urine flow and free water clearance (as well as osmolar clearance) were greater in the hypertensive patients than in the normal subjects.

TABLE III

Sodium excretion* during and after infusion

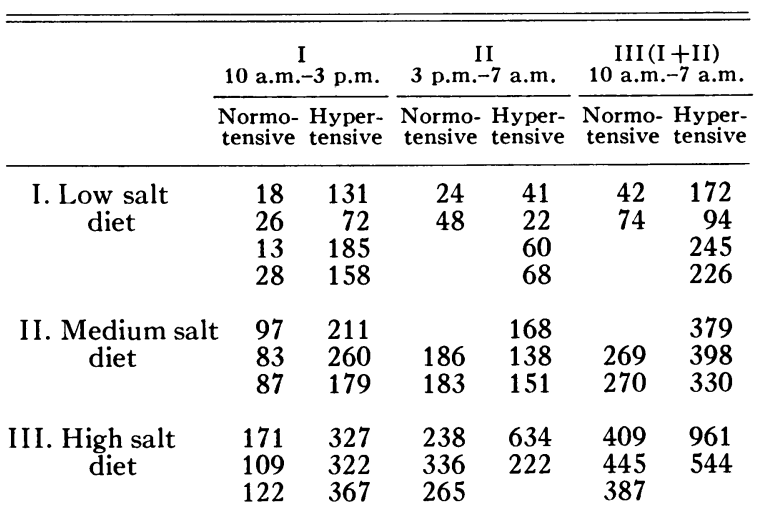

* Total number of milliequivalents excreted in each time interval.
9. Serum concentration of sodium and chloride did not change significantly $(-1$ to $+3 \mathrm{mEq}$ per L) following the infusion of the sodium chloride-lactate solution. A small decrease in hematocrit (1 to 4 points) and total protein concentration ( 0.2 to $1.1 \mathrm{~g}$ per $100 \mathrm{ml}$ ) was observed following infusion.

\section{DISCUSSION}

The present study confirms other observations that patients with essential hypertension have a greater natriuretic response to administered salt solution than have normal individuals. In addition it establishes the fact that this difference in sodium excretion is short-lived and is not due to differences in dietary ingestion of salt prior to the test. Indeed, the data demonstrate that the exaggerated natriuresis of the hypertensive individual is apparent at all levels of salt intake ranging from 10 to $300 \mathrm{mEq}$ daily. Furthermore, the study suggests that the difference in natriuretic response is probably not due to an alteration in diurnal rhythm. Thus, on Blank Days on the low salt diet, the normal and the hypertensive subjects excreted comparable quantities of sodium. The present data do not provide final proof on this point since the change in sodium excretion (peak minus control) on Blank Days was greater in the patients with hypertension than in the normal subjects. This difference seems to be related primarily to a generally lower control ( $8: 30$ to 10 a.m.) rate of sodium excretion in the hypertensive subjects on Blank Days, compared with the normal individuals, rather than to a consistently higher peak excretory rate for sodium. That this may have been fortuitous is perhaps suggested by the fact that the preinfusion values on Infusion Days while taking the low salt diet do not bear out this difference in control values. Clearly, more studies are required to resolve the role of diurnal rhythm with complete certainty. That the hypertensive subject excreted more sodium than did the normal individual on Blank Days at medium and high dietary levels is probably due to the fact that added salt was taken on these days at breakfast time and in effect constituted a small but effective "salt load." In addition, the present study makes it quite clear that the exaggerated natriuretic response is not due to a difference in baseline rates of sodium excretion 
prior to infusion. Finally, the infusate was such that serum sodium concentration was not changed significantly during any experiment, thus precluding the possibility that the exaggerated natriuresis may be related to a peculiarly distorted response to hypertonic salt solutions in patients with hypertension.

While the present study documents the existence of abnormal sodium excretion in hypertension under controlled conditions, the data do not provide an understanding of the mechanisms involved. In these studies, as in others, in which there is no consistent relationship between endogenous creatinine clearance (or inulin clearance) and sodium excretion, it is virtually impossible to establish or exclude the importance of small but significant changes in glomerular filtration rate in determining differences in sodium excretion. From the present studies it would appear that the exaggerated natriuretic response is not clearly attributable to increased glomerular filtration rate either in the basal period or in response to salt administration. Consequently, it seems reasonable to focus attention on the renal tubular handling of sodium in patients with hypertension. The possibility exists that the renal tubular cell itself is abnormal or that a normal tubular cell is responding normally to abnormal influences or to stimuli that are abnormally mediated. While a specific tubular "defect" cannot be excluded, there is little evidence in support of this concept (7). Among the variety of known and unknown extrarenal factors that might influence renal tubular handling of sodium in the hypertensive patient are hormonal factors (e.g., adrenocortical and adrenomedullary), neurogenic factors and intrarenal circulatory phenomena (8). There is little direct evidence to support the causal role of any of these at the present time. The amount of sodium in the body, perhaps as expressed in terms of "effective" extracellular fluid volume, seems to be an important determinant of sodium excretion in the normal individual (8). How the kidney is made aware of changes in this factor is not at all clear. There are data which suggest increased total body sodium as well as increased extracellular fluid volume in patients with essential hypertension, although other data are not in accord with these findings (13-17). Nonetheless, no causal relationship between al- terations in extracellular volume or body sodium content and the observed exaggerated natriuretic response to administered sodium seems warranted by the data at this time. The present study does not clarify the relationship of the disturbances in sodium excretion to other aspects of the condition called "essential hypertension," including the elevation of blood pressure.

\section{SUMMARY AND CONCLUSIONS}

1. The natriuretic response to the infusion of an isotonic solution of sodium chloride-lactate was studied in four normal subjects and in six patients with essential hypertension, under conditions rigidly controlled in respect to the amount of sodium ingested, posture, and time of day.

2. At each of three levels of daily sodium ingestion $(10,150$ and $300 \mathrm{mEq})$ the patients with hypertension had a far greater natriuretic response to administered sodium than had the normal individuals.

3. Without infusion, at the low salt dietary level, there was no difference in the quantity of sodium excreted between normal subjects and patients with hypertension, suggesting that variations in basic diurnal rhythm probably do not account for the enhanced rate of sodium excretion.

4. The exaggerated natriuresis is not attributable to differences in preinfusion rates of sodium excretion or to greater increase in serum sodium concentration. In addition, the difference in natriuresis following infusion between the hypertensive and normotensive subjects is not associated with clearly consistent differences in endogenous creatinine clearance or further augmentation in blood pressure.

5. The "abnormal" response to salt administration in patients with essential hypertension remains unexplained.

\section{REFERENCES}

1. Green, D. M., Wedell, H. G., Wald, M. H., and Learned, B. The relation of water and sodium excretion to blood pressure in human subjects. Circulation 1952, 6, 919.

2. Birchall, R., Tuthill, S. W., Jacobs, W. S., Trautman, W. J., Jr., and Findley, T. Renal excretion of water, sodium and chloride. Comparison of the responses of hypertensive patients with those of 
normal subjects, patients with specific adrenal or pituitary defects, and a normal subject primed with various hormones. Circulation 1953, 7, 258.

3. Thompson, J. E., Silva, T. F., Kinsey, D., and Smithwick, R. H. The effect of acute salt loads on the urinary sodium output of normotensive and hypertensive patients before and after surgery. Circulation 1954, 10, 912.

4. Hollander, W., and Judson, W. E. Electrolyte and water excretion in arterial hypertension. I. Studies in non-medically treated subjects with essential hypertension. J. clin. Invest. 1957, 36, 1460.

5. Cottier, P. T., Weller, J. M., and Hoobler, S. W. Effect of an intravenous sodium chloride load on renal hemodynamics and electrolyte excretion in essential hypertension. Circulation 1958, 17, 750.

6. Baldwin, D. S., Biggs, A. W., Goldring, W., Hulet, W. H., and Chasis, H. Exaggerated natriuresis in essential hypertension. Amer. J. Med. 1958, 24, 893.

7. Hanenson, I. B., Taussky, H. H., Polasky, N., Ransohoff, W., and Miller, B. F. Renal excretion of sodium in arterial hypertension. Circulation 1959, 20, 498 .

8. Strauss, M. B. Body Water in Man. Boston, Little, Brown, 1957.

9. Strauss, M. B., Lamdin, E., Smith, W. P., and Bleifer, D. J. Surfeit and deficit of sodium. A. M. A. Arch. intern. Med. 1958, 102, 527.
10. Dahl, L. K., and Love, R. A. Evidence for relationship between sodium (chloride) intake and human essential hypertension. A. M. A. Arch. intern. Med. 1954, 94, 525.

11. Dahl, L. K. Evidence for increased intake of sodium in hypertension based on urinary excretion of sodium. Proc. Soc. exp. Biol. (N. Y.) 1957, 94, 23.

12. Strauss, M. B., Davis, R. K., Rosenbaum, J. D., and Rossmeisl, E. C. "Water diuresis" produced during recumbency by the intravenous infusion of isotonic saline solution. J. clin. Invest. 1951, 30, 862.

13. Grollman, A., and Shapiro, A. P. The volume of the extracellular fluid in experimental and human hypertension. J. clin. Invest. 1953, 32, 312.

14. Taquini, A. C., Plesch, S. A., Capris, T. A., and Badano, B. N. Some observations on water and electrolyte metabolism in essential hypertension. Acta cardiol. (Brux.) 1956, 11, 109.

15. Teng, H. C., Shapiro, A. P., and Grollman, A. Volume of the fluid compartments in human and experimental hypertension. Metabolism 1954, 3, 405.

16. Ross, E. J. Total exchangeable sodium in hypertensive patients. Clin. Sci. 1956, 15, 81.

17. DeGraeff, J. Inulin space and total exchangeable sodium in patients with essential hypertension. Acta med. scand. 1957, 156, 337. 